\title{
Appliances Monitoring and Dynamic Controlling of Power
}

\author{
Pournima P. Patil \\ PG Research Scholar, Department of ETC, \\ SVIT, Chincholi, Nasik, Maharashtra, India
}

\author{
Liladhar. P. Bhamare \\ Asst. Professor, Department of ETC \\ SVIT, Chincholi, Nasik, Maharashtra, India
}

\begin{abstract}
Energy crises in the country is great bottleneck. There is huge demand of energy all over the globe. We lose so much energy, particularly in the old system. Energy issues and technology change have played crucial roles in energy saving. Electrical appliances used in the past consume most of the power [1-5] and even though todays most of the electrical appliances are having inbuilt features for power management. These appliances are used everywhere in the offices and home. These appliances are computers, computer peripherals such as a monitors, printers. But all the time these will never get shutdown. But they go into sleep mode or idle mode, but still they consume energy. This is avoided in the proposed system, where these appliances are made OFF. These are made ON as on when required by giving trigger when we work on it. This embedded system saves $10 \%$ overall power consumed in a year.
\end{abstract}

\section{General Terms}

Low Power, Energy Consumption

\section{Keywords}

Standby Power, Energy Saving, appliances, dynamic Controlling, Dynamic energy management system (DEMS)

\section{INTRODUCTION}

Many small businesses are connected through the technology. The energy use of small office equipments in the small business may account $18 \%$ of overall energy bills.[6-8] One can stop paying such increased in the bill and spend the same amount in business. Business will grow. Simple change to the way one use office equipments and monitors these office equipments through the system will definitely increase energy saving. There is huge demand of such system which can save energy as well as optimum use of office equipments[14-16]. Office electrical equipments in which computer peripherals such as monitor, printer plays important role energy consumption. There are different ways to control it. 1) One can turn off monitor if you are not using it for more than 30 minutes. 2) Switch of all the equipments after office hours and weekends. These equipments should be off and ensure it should not be in sleep mode. 3) One can install timer equipments to turn off the office equipments. Computer equipments contribution in standby and sleep mode contributes lots of energy. There is more than $40 \%$ to $90 \%$ of the total energy waste from computer peripherals standby mode. [9-13]

These ways stated above can result it into significant cost saving:

\author{
1. Energy consumption \\ 2. Maintenance cost \\ 3. Replacement costs, \\ 4. Operating life of equipments and, \\ 5. Running cost
}

This paper is structured in six sections, section-I give introduction, section-II gives methodology, proposed system is given in the section-III, section IV shows implementation of system, section $\mathrm{V}$ gives software implementation and section VI draws conclusion.

\section{METHODOLOGY}

In this project a circuit is designed and implemented into any electrical appliances to reduce this standby power. The paper deals with a printer, which consume standby power of $90 \mathrm{~W}$ is reduced where a low standby power achieved. The printer power consumption is monitored and it is connected to the analog input of the microcontroller. In this simulation we connected the Trim pot for adjusting the current input to the microcontroller. Current consumption go below $90 \mathrm{~W}$ the microcontroller turns off the relay. Then the printer power shuts off.

The door switch output signal is connected to the input of the MCU. If the door is opened, the MCU wakes up from its sleep mode and turns on the relay. So the printer power switched on, thus enabling the printer and allowing the user to set the control panel. The keypad output is also connected to the input of the MCU. If the keypad is pressed, the printer power is switched on. This variation in its operating mode is indicated by the LED design circuit. Its power consumption and the implement results are compared and explained. The circuit designed for low standby power consumption can be implemented in any of the future electrical appliances due to its low cost simple design and its flexibility.

\section{PROPOSED SYSTEM}

Block diagram of proposed system is shown in figure 1. This is divided into four parts.

1. Microcontroller

2. Power sensing circuit.

3. Appliances Triggering unit.

4. Appliances under control. 


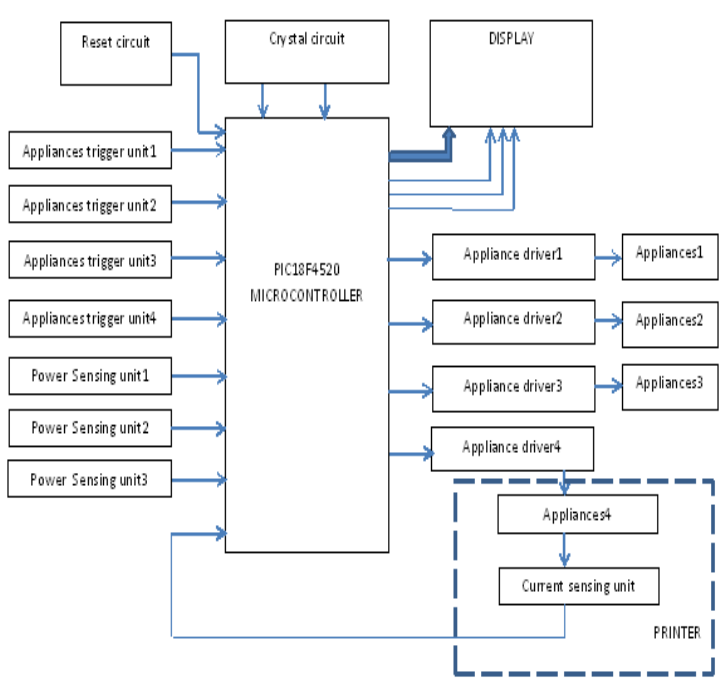

Fig. 1: Proposed system of energy saving

\subsection{Microcontroller}

It is heart of the system. This is a microcontroller which takes decision based on the inputs of appliances. It gives trigger to appliances for making ON/OFF.

\subsection{Power sensing circuit.}

This unit consists of signal conditioning circuit which will sense the current and voltage of the appliance [7]. There are different currents in the different mode of appliance. Different modes are a) Idle mode b) Power down mode c) Shut down mode.

\subsection{Appliances Triggering unit.}

This unit consists of a circuit which will sense the appliance whenever it is operated by a user. Even though this appliance is in any mode Idle mode, Power down mode, Shut down mode. This will give signal to microcontroller and these appliances will immediately come in the operating mode where it will activate all its functions

\subsection{Appliances under control.}

There are different appliances which are need to control such as computer peripherals like printers, scanner. Workgroup printer draws $800 \mathrm{w}$ during printing and 90w during standby mode. Mid-workgroup printer is about $500-800 \mathrm{~W}$ in use and $80 \mathrm{~W}$ during standby mode. Most of this is heating up the fuser. To save energy it is best to turn off the printer when not being used. In ideal mode current is very small, this current is sense [17] by signal conditioning circuit which is given to PIC18F4520 through internal ADC. PIC microcontroller will tale decision based on the amount of current.

\section{HARDWARE IMPLEMENTATION}

Implementation of the system is shown in fig 2

Pin out of the circuit design is as given as below

1. LCD INTERFACING
a. LCD data PORTC
b. LCD RS RD6
c. LCD EN RD7

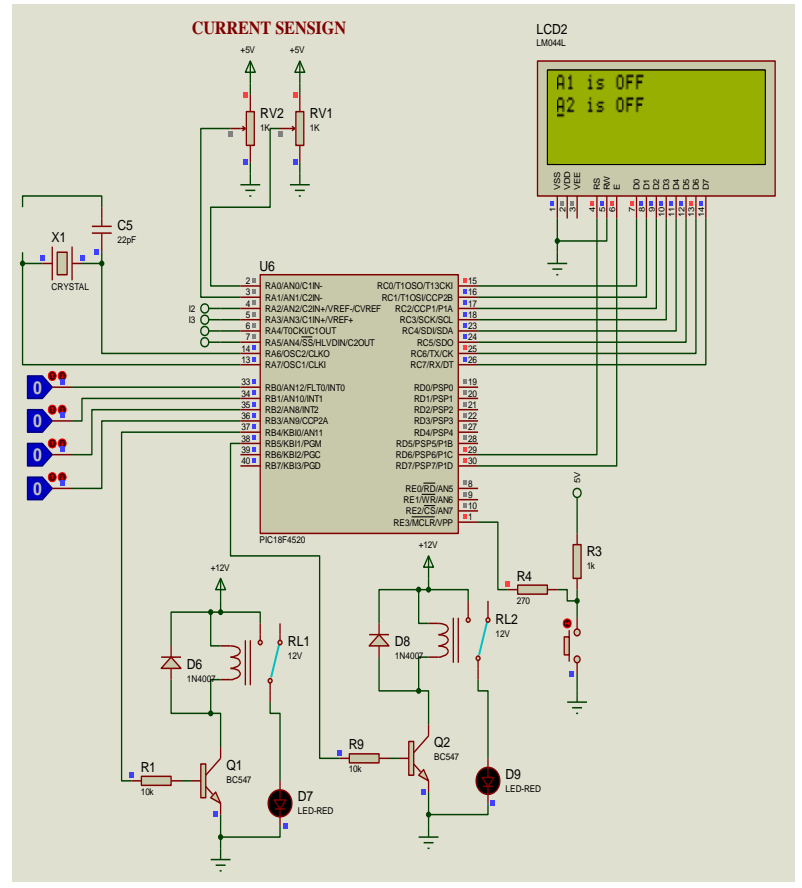

Fig. 2 System Circuit diagram

2. Appliances triggering

a. PORT B0-B3

3. Appliances ON/OFF

a. PORT B4-B7

4. Current sensing

5. ADC input ANALOG A0-A4

Pin out which is assigned with PIC18F4520 is shown in figure 3.

Appliances current are measured at analog channel, if current is less than the standby, it gives signal to relay driver circuit. Relay driver circuit will switch off the Appliances. If the user want use appliances, he will touch the keypad of the appliances which will give trigger automatically to the microcontroller which in turns ON the Relay and appliances get activated. This will go on continuing till the current of the appliances go down to level of standby current.

\subsection{Microcontroller}

Power Management Features of PIC18F4520:

- Run: CPU on, Peripherals on

- Idle: CPU off, Peripherals on

- Sleep: CPU off, Peripherals off

- Ultra Low 50nA Input Leakage

- Run mode Currents Down to $11 \mu \mathrm{A}$ Typical

- Idle mode Currents Down to $2.5 \mu \mathrm{A}$ Typical

- $\quad$ Sleep mode Current Down to 100 nA Typical

- Timer1 Oscillator: $900 \mathrm{nA}, 32 \mathrm{kHz}, 2 \mathrm{~V}$

- Watchdog Timer: $1.4 \mu \mathrm{A}, 2 \mathrm{~V}$ Typical

- Two-Speed Oscillator Start-up 
Features of PIC18F4520 shows that it is low power microcontroller. Design of PIC18F4520 is shown in fig 3. Capacitor selection is values are shown in Table I.

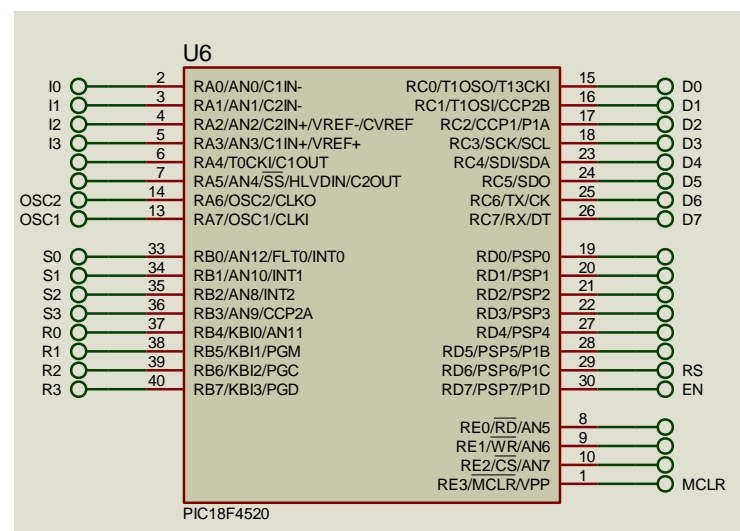

Fig. 3 Microcontroller pin out diagram

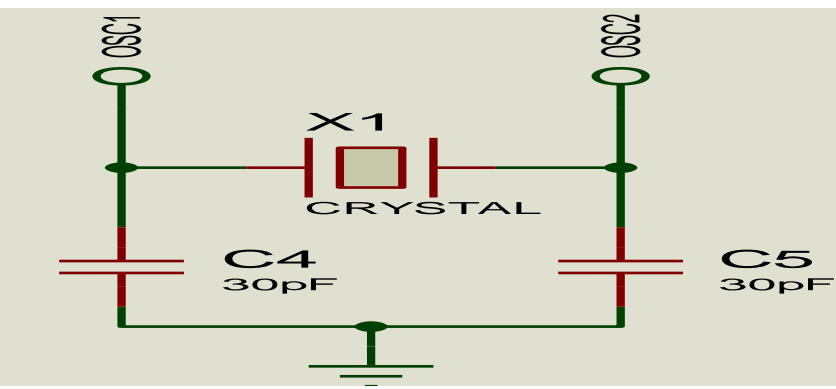

Fig. 4 Crystal circuit design

Table-I typical capacitor values used in crystal

\begin{tabular}{|c|c|c|c|}
\hline Mode & Freq & OSC1 & OSC2 \\
\hline XT & $3.58 \mathrm{MHz}$ & $15 \mathrm{pF}$ & $15 \mathrm{pF}$ \\
& $4.19 \mathrm{MHz}$ & $15 \mathrm{pF}$ & $15 \mathrm{pF}$ \\
& $4 \mathrm{MHz}$ & $30 \mathrm{pF}$ & $30 \mathrm{pF}$ \\
& $4 \mathrm{MHz}$ & $50 \mathrm{pF}$ & $50 \mathrm{pF}$ \\
\hline
\end{tabular}

Appliances ON/OFF status is shown in fig. 5

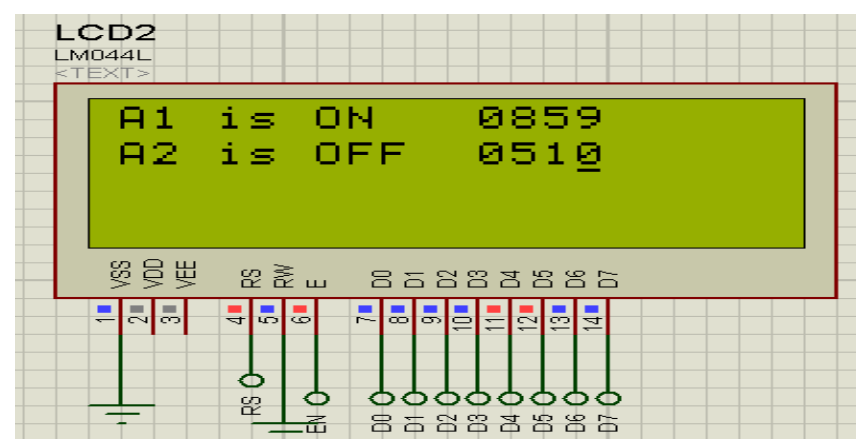

Fig. 5 LCD display interface with microcontroller

\subsection{Current Sensing Circuit}

Here we have made attempt to show through simulated sensor. A variable register is used in the input of ADC channel. It reads the change $\mathrm{n}$ current. When the change in current go below specified limt. It switch off the appliances.

\subsection{Appliances Triggering unit.}

This unit consists of trigger circuit which gives trigger whenever the keyboard or panel of the printer is touch or open, the input singal generated and is given to PIC microcontroller which in turns makes the device $\mathrm{ON}$.

\subsection{Appliances under control.}

A Relay driver circuit is designed as a switch which is controlled by transistor. As soon as signal is given by controller to this unit, it activate appliances. Figure 6 shows the appliances ON/OFF controller.

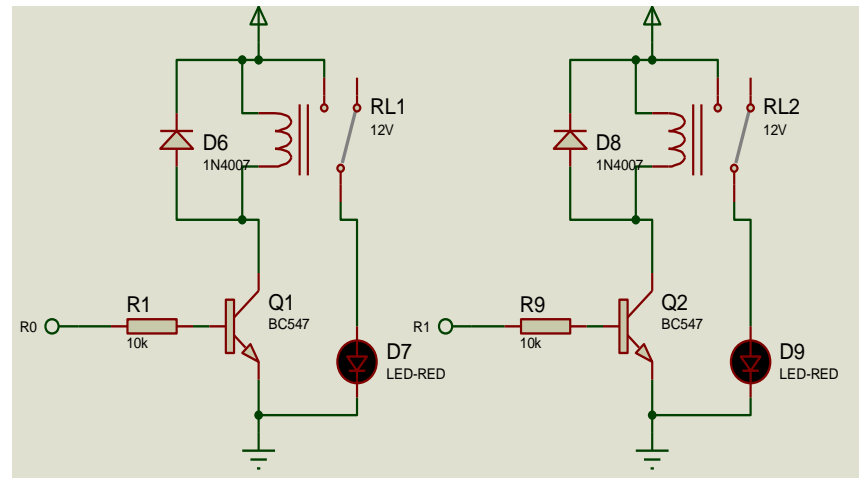

Fig. 6 Appliances ON/OFF controller

\section{SOFTWARE IMPLEMENTATION 5.1 MPLAB IDE}

Is software program that runs on windows to develop applications for microchip microcontrollers and digital controllers. It provide a development environment for your embedded system design.

\subsection{Compiler}

MPLAB compilers produces highly optimize code it supports all the microchip devices.

\section{Algorithms}

1. It check appliances trigger or not

2. Check current is more than standby current

3. If trigger receives, it will make appliances $\mathrm{ON}$

4. Continuously monitoring the current till it is more than standby current.

5. If current go below standby it will OFF the Appliances. Go in step 1. 


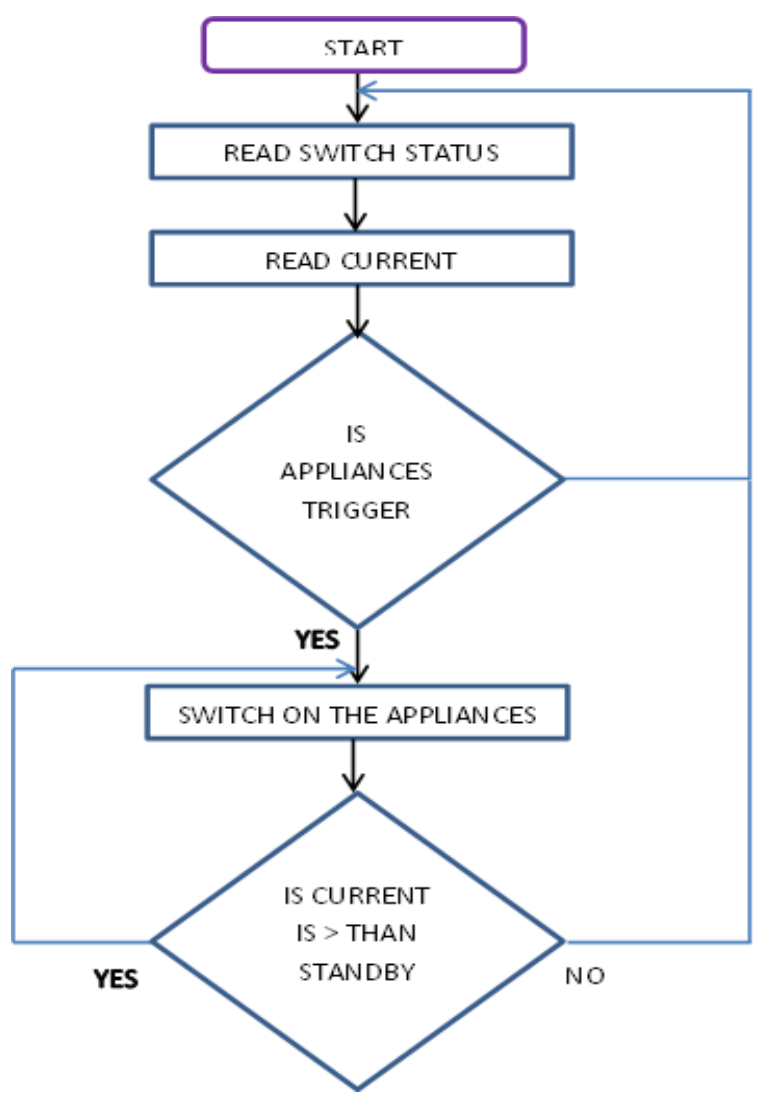

Fig. 7 Flow chart of the program

\section{CONCLUSION}

This paper proposes a new system design which remarkably reduces the standby power of printer used in offices and home specially laser printer. It also monitors all the equipments in the home/offices. This also reduces continuous monitoring of human which is quite tedious and also costly. These are made on as on when required by giving trigger when we work on it. This embedded system saves $10 \%$ overall power consumed in a year.

\section{REFERENCES}

[1] U.S. Department of Energy, "Energy Saver Booklet: Tips on Saving Energy \& Money at Home," May. 2009.

[2] Ying-Wen Bai, and Yi-Te $\mathrm{Ku}$, "Automatic room light intensity detection and control using a microprocessor and light sensors," IEEE Trans.Consumer Electron., vol.54, no.3, pp.1173-1176, August 2008

[3] Ying-Wen Bai, Zi-Li Xie, and Zong-Han Li, "Design and implementation of a home embedded surveillance system with ultra-low alert power,'IEEE Trans. Consumer Electron., vol.57, no.1, pp.153- 159, February 2011.

[4] Suk Lee, Kyoung Nam Ha, and Kyung Chang Lee, "A pyroelectric infrared sensor-based indoor location-aware system for the smart home,"IEEE Trans. Consumer Electron., vol.52, no.4, pp.1311-1317, Nov. 2006.

[5] Sunghoi Parka, Myeong-in Choia, Byeongkwan Kanga, Sehyun Parka, "Design and Implementation of Smart Energy Management System for Reducing Power Consumption using ZigBee Wireless Communication Module", page no 662-668 Elsevier 2013

[6] Prof. Lalit Kumar Wadhwa1, Hemangi Vinchurkar2, Mugdha V. Patil3, "Design and Implementation of Zero
Standby Power System Using PIR Luminaire, IJAREEIE Vol. 3, Issue 7, July 2014" 10580-10587.

[7] S. Philomina, "Sophisticated Home Appliance Control System Using Embedded Linux",Middle-East Journal of Scientific Research 20 (12): 1873-1878, 2014.

[8] Shun-Chieh Lin, Huan-Wen Tsai, Yi-Lin Chiang and Tsung-Lin Tsai,"Design and Implementation of an Adaptive Control Mechanism for Standby Power Detection and Saving",International Conference on Affective Computing and Intelligent Interaction Lecture Notes in Information Technology, 295-303 Vol.10 ICACII2012.

[9] Jiin-Hwa Yang, Hui-Li Weng, Wen-Sen Tseng, and Heng-Fa Teng,"Implementation of Power Reduction in the Homes of Older People", International Conference on Gerontic Technology and Service Management, University of Technology, Nantou, Taiwan Apripage no. $1-4,2010$

[10] Cheng-Hung Tasi, Ying-Wen Bai, Chun-An Chu, Chih$\mathrm{Yu}$ Chung and Ming-Bo Lin,"Design and Implementation of a Socket with Ultra-Low Standby Power", IEEE 1216-1221, 2011

[11] Niks?a Skeledz?ija, Josip C' esic', Edin Koc?o, Vladimir Bachler, Hrvoje Nikola Vuc?emilo, Hrvoje Dz?apo, "Smart Home Automation System for Energy Efficient Housing", MIPRO 2014, pp 161-171, 26-30 May 2014

[12] Laxmi Soni1, Sarika K. Thorat2 And Sandeep Chawda3,"PC Controlled Home Appliances",Int. Journal of Engineering Research and Applications,ISSN : 2248 9622, Vol. 4, Issue 5( Version 1), pp.51-53, May 2014,

[13] Swapnil Pujari Amol Jirage M. R. Madki,Optimization for Standby Power Reduction Control Mechanism using Bluetooth,International Conference in Recent Trends in Information Technology and Computer Science (ICRTITCS - 2012) Proceedings published in International Journal of Computer Applications ${ }^{\circledR}$ (IJCA) (0975 - 8887) pp 11-14, 2012

[14] Kyoung-Mi Im, Jae-Hyun Lim," An Intelligent Standby Power Control System Design based on User Location and Appliance Usage Pattern in Smart Home", Journal of Convergence Information Technology(JCIT), pp 12311241, Volume8, Number8, April 2013

[15] Poshavoni Vikas Yadav, Prof. N Umaheshwar Rao, "Standby Power Management of Microwave-Oven", International Journal of Science, Engineering and Technology Research, ISSN: 2278 - 7798 Volume 3, Issue 9, September 2014

[16] Inderpreet Kaur, "Microcontroller Based Home Automation System With Security", (IJACSA) International Journal of Advanced Computer Science and Applications, Vol. 1, No. 6, December 2010.

[17] Wei-Ting Cho1, Chin-Feng Lai2, Yueh-Min Huang3, Wei-Tsong Lee4 and Sing-Wei Huang5,"Home Energy Management System for Interconnecting and Sensing of Electric Appliances",KSII TRANSACTIONS ON INTERNET AND INFORMATION SYSTEMS VOL. 5, NO. 7, July 2011 